\title{
Exploring community health worker roles, support, and experiences in the context of the COVID-19 pandemic in Haiti
}

Frontline Health Project

Zanmi Lasante

Follow this and additional works at: https://knowledgecommons.popcouncil.org/departments_sbsr-rh How does access to this work benefit you? Let us know!

\section{Recommended Citation}

Frontline Health Project and Zanmi Lasante. 2021. "Exploring community health worker roles, support, and experiences in the context of the COVID-19 pandemic in Haiti," Frontline Health Results Brief. Washington, DC: Population Council. 


\section{EXPLORING COMMUNITY HEALTH WORKER ROLES, SUPPORT, AND EXPERIENCES IN THE CONTEXT OF THE COVID-19 PANDEMIC IN HAITI}

\section{BACKGROUND}

Community health workers (CHWs) are critical actors within community health systems, providing a range of reproductive, maternal, child, and primary health information, counseling, and services. As community members themselves, CHWs understand the local context and facilitate linkages to care [1]. In pandemics like COVID-19, they continue to provide routine services in addition to undertaking increased responsibilities. While CHWs are innovative in their strategies to sustain their work, they operate under challenging circumstances including limited guidance and support as well as potential hostility from communities and/or facility-based providers.

In Haiti, CHWs - locally called "agents de santé communautaire polyvalent" (ASCPs) - are the primary deliverers of health information and services. ASCPs are expected to make 100 home visits per month, during which they counsel and provide health services at the household level and refer and accompany individuals to health facilities for various issues, including malnutrition, communicable and non-communicable diseases, mental health crises, and during emergencies [2].

In Haiti, COVID-19 was first detected in March 2020, and there were just over 12,663 cases and 250 confirmed deaths as of March 82021 [3]. At the national level, in addition to enacting several strategies to mitigate the spread of COVID-19 early on, the Ministry of Public Health and Population (MSPP) implemented precautionary measures aimed at strengthening and adapting the COVID-19 surveillance system to detect early cases and contain the spread of the disease. The continuance of community health service delivery during COVID-19 primarily falls upon ASCPs.

This brief presents results from the Frontline Health project's study in Haiti which aims to explore the perspectives of ASCPs on educating communities, providing care, and health reporting during the pandemic.

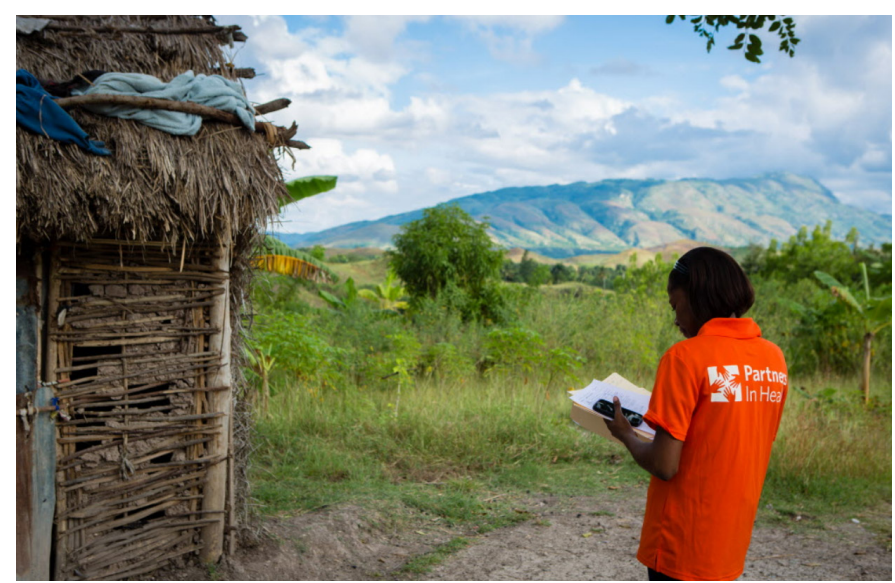

Photo: Zanmi Lasante

\section{KEY FINDINGS}

1. During the COVID-19 pandemic in Haiti, ASCPs continue their routine work visiting households and providing health services at increased levels compared to before the pandemic, with some disruptions in group activities such as rally posts and community health events.

2. ASCPs are educating households and connecting clients to advanced care for COVID-19; however, they are not receiving adequate PPE/supplies and support to perform their work.

3. Providing adequate PPE/infection prevention supplies; training on COVID-19 screening, reporting, and referring; and further exploring experiences of hostility may help alleviate challenges $\mathrm{CHWs}$ face while educating communities and providing services during the COVID-19 pandemic. 


\section{RESULTS}

The majority of ASCPs are between 36 - 55 years, highly educated, and have 5 - 10 or more years of experience as a CHW.

The Frontline Health project surveyed 261 ASCPs providing routine services during the pandemic and found that the slight majority (56\%) are male and most are between $36-45$ years old (39\%) and $46-55$ years old (30\%). ASCPs in our sample are well-educated, with $97 \%$ reporting that they completed secondary education or higher. Most ASCPs reported that they had been working for 5-10 years (53\%) or over 10 years (27\%) (Table 1).

Similar to the main mode of transport being by foot prior to the onset of COVID-19, our survey found that almost three-quarters of ASCPs continue to travel to households by foot (73\%), followed by motorbike (12\%) and bike taxi (11\%) during the pandemic.

ASCPs continue to provide routine services, with additional COVID-19 responsibilities due to the pandemic.

Our data indicate that the majority of ASCPs were able to carry out their routine household visits and community education at the onset of the pandemic; however, group activities such as rally posts and community meetings were canceled. When asked whether they were able to carry out their routine work within the first month after the pandemic broke out, almost $85 \%$ of ASCPs $(n=261)$ reported that they were able to do so "mostly" or "somewhat", leaving $15 \%$ $(n=38)$ of ASCPs unable to carry out their routine work at all (data not shown).

Initial reasons for ASCPs' not being able to carry out their routine work one month into the pandemic include a lack of guidelines (92\%), medical safety concerns (87\%), physical security concerns (79\%), a lack of transport (16\%), community refusal due to fear of infection (11\%) and work shifting entirely to COVID-19 (8\%) (Figure 1, pg. 2).

Six months into the pandemic, the majority of ASCPs reported that they were able to carry out their routine work "somewhat" or "mostly" (95\%) and only 5\% reported not being able to carry out their routine work at all $(n=14)$ (data not shown).
ASCPs are providing services at higher levels and more frequently during the first six months of the pandemic than prior.

Given the high proportions of service provision prior to the onset of COVID-19, the percentage of ASCPs providing various routine services stayed the same or increased slightly during the pandemic.

TABLE 1. CHARACTERISTICS OF ASCPS ( $\mathbf{N}=\mathbf{2 6 1}$ )

\begin{tabular}{|c|c|}
\hline Characteristic & $\begin{array}{c}\text { Total } \\
(\%)\end{array}$ \\
\hline \multicolumn{2}{|l|}{ Gender } \\
\hline Female & 44 \\
\hline Male & 56 \\
\hline \multicolumn{2}{|l|}{ Age } \\
\hline 19-25 Yrs & 1 \\
\hline 26-35 Yrs & 20 \\
\hline 36-45 Yrs & 39 \\
\hline 46-55 Yrs & 30 \\
\hline $56-65$ Yrs & 10 \\
\hline \multicolumn{2}{|l|}{ Education level } \\
\hline Some primary & 3 \\
\hline Secondary & 87 \\
\hline More than secondary & 10 \\
\hline \multicolumn{2}{|l|}{ Time working as an ASCP } \\
\hline$<5$ years & 21 \\
\hline 5 - 10 years & 52 \\
\hline$>10$ years & 27 \\
\hline \multicolumn{2}{|l|}{ Received incentives } \\
\hline Monthly stipend & 99.6 \\
\hline Allowances (transport, lunch, airtime) & 22 \\
\hline Non-financial (food, backpacks) & 2 \\
\hline None & 1 \\
\hline \multicolumn{2}{|l|}{ Time to reach farthest household } \\
\hline Below 30 minutes & 39 \\
\hline $30-60$ minutes & 24 \\
\hline $61-120$ minutes & 24 \\
\hline Above 120 minutes & 13 \\
\hline \multicolumn{2}{|l|}{ Main mode of travel since pandemic } \\
\hline By foot & 73 \\
\hline Bicycle & 1 \\
\hline Motorbike & 12 \\
\hline Bus & 3 \\
\hline Easy bike taxi & 11 \\
\hline
\end{tabular}


The percentage of ASCPs that reported providing counseling and direct primary health care services increased from $96 \%$ before the pandemic to $99 \%$ six months into the pandemic, and the percentage of ASCPs providing immunizations for children increased from $91 \%$ to $96 \%$ (Figure 2).

ASCPs also reported providing higher levels of mental health counseling, education on water, sanitation, and hygiene (WASH), and increased referrals for gender-based violence (GBV), among others (data not shown).

ASCPs reported slightly decreased in-person supportive supervision during the pandemic.

Most ASCPs reported being supervised through regular/scheduled in-person one-on-one meetings with their supervisors (97\%) or team meetings (98\%) prior to the pandemic; however, the percentage of ASCPs reporting these in-person methods lessened to $92 \%$ and $94 \%$, respectively, during the pandemic. The percentage of ASCPs reporting digital communications and phone calls slightly decreased as well (data not shown). This signals that ASCPs are receiving less frequent supportive supervision than they were prior to the pandemic.

ASCPs reported engaging in various activities in their communities related to COVID-19 prevention, treatment, and reporting.

Almost $98 \%$ of ASCPs $(n=255)$ reported that they received any training/guidance on what to do around COVID-19; however, the percentage of ASCPs receiving training/guidance on specific aspects of the

\section{FIGURE 1. ASCPS' REPORTED REASONS FOR NOT CARRYING OUT ROUTINE TASKS IN THE FIRST MONTH OF THE PANDEMIC $(\mathbf{N}=\mathbf{3 8})$}

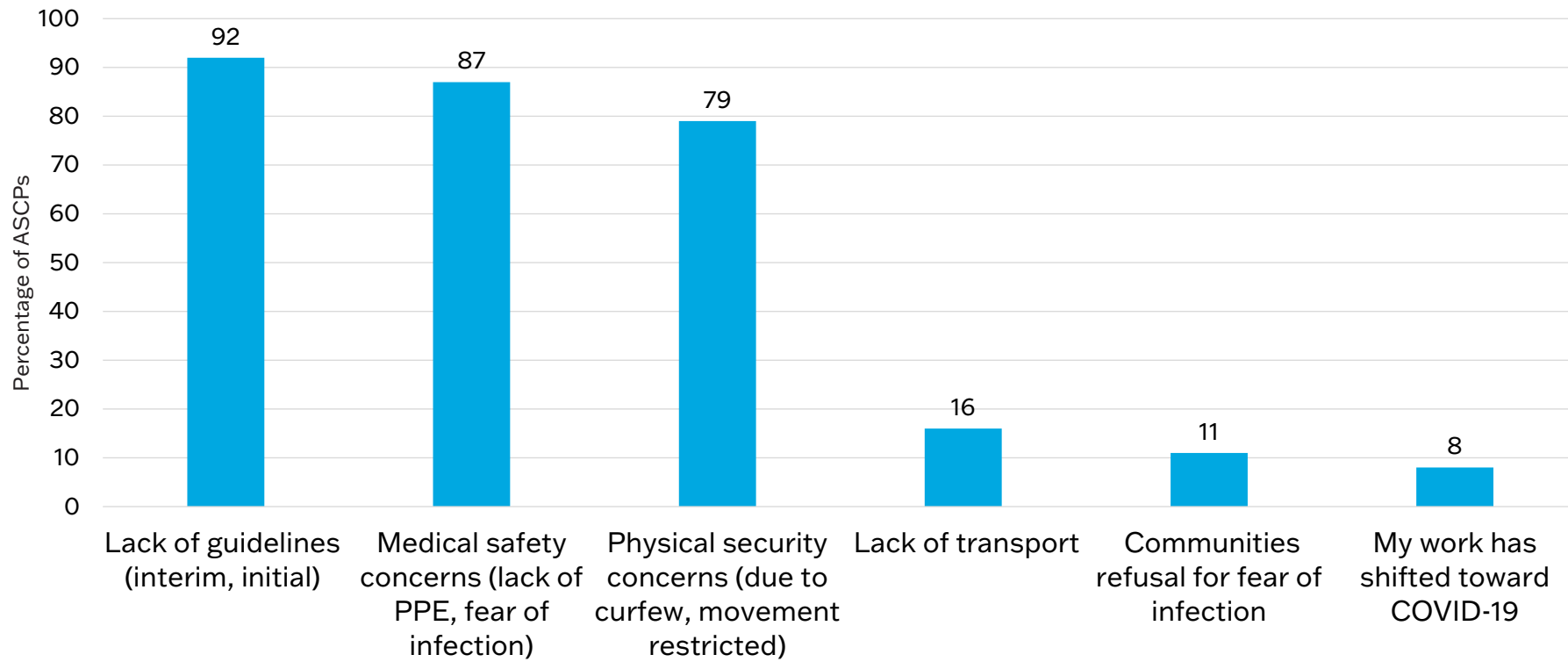

FIGURE 2. CHWS' RESPONSIBILITIES BEFORE AND DURING THE PANDEMIC ( $\mathbf{N}=\mathbf{2 6 1})$

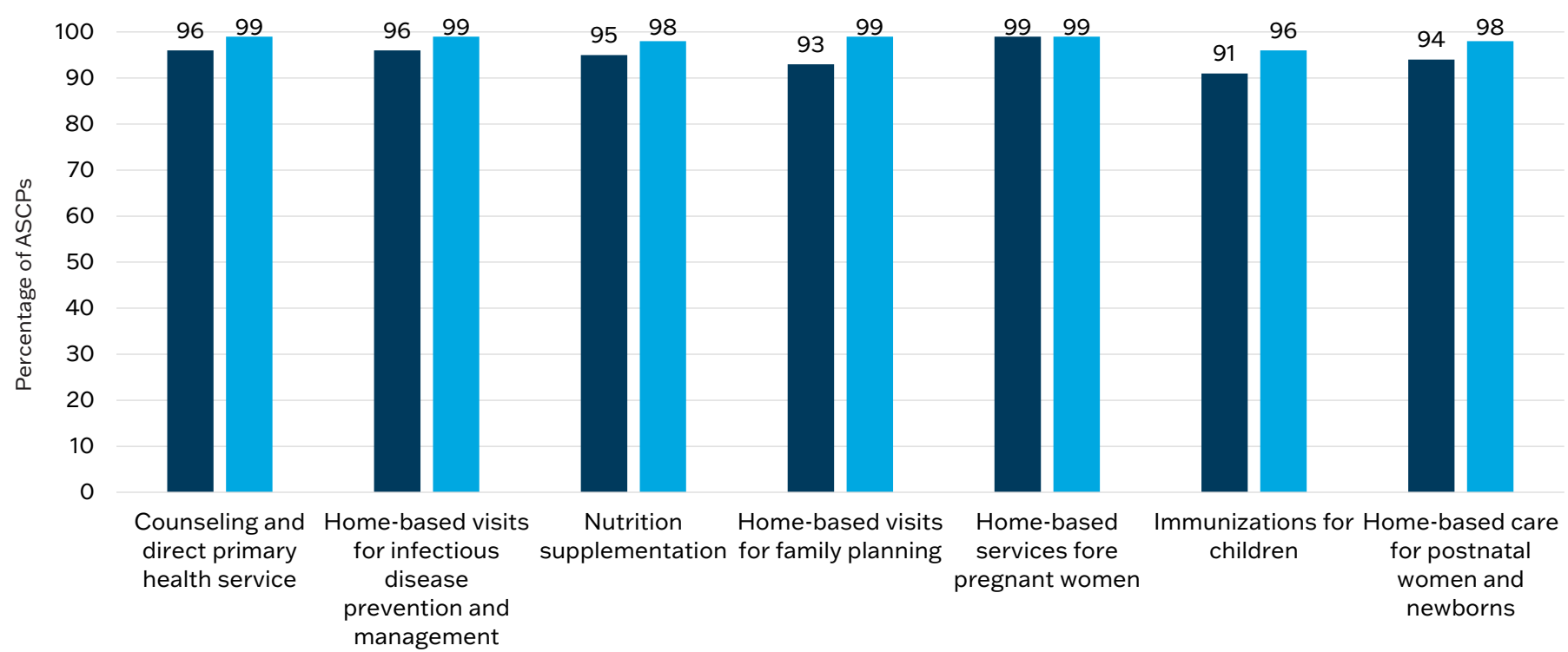


pandemic such as contract tracing and continuity of home-based care varied (Table 2). This indicates there may be gaps in specific aspects of COVID-19 training for ASCPs which warrant further exploration.

Ninety-seven percent of ASCPs $(n=261)$ reported that they were providing COVID-19 services separate from their routine duties at the time of the survey (making up "all" or "some" of their work), and 99\% ( $n=259)$ reported educating community members about COVID-19 prevention or treatment (Table 3). While almost all ASCPs reported giving specific advice to their communities on prevention and treatment such as wearing masks, frequent hand washing/sanitizing, and social distancing, fewer ASCPs reported giving advice on what to do if exposed or symptomatic (Figure 3 ).

While $95 \%$ of ASCPs reported educating community members about how to take care of someone with COVID-19 in the home, fewer reported engaging in activities related to referrals and reporting. Nearly one in three ASCPs reported referring suspected COVID-19 cases for testing, one in four reported referring suspected cases for advanced care at facilities, and one of four reported suspected or confirmed cases of COVID-19. Thirty-five percent of ASCPs reported contact tracing for those who may have had COVID-19 in the community in which they serve (Table 3).

\section{ASCPs faced COVID-19-related challenges while carrying out their routine services.}

ASCPs reported various challenges in the context of the pandemic, including being unable to travel due to social distancing regulations, inadequate or missing PPE, fears of spreading or contracting COVID-19, and shortages of contraceptives, drugs, and other commodities (Table 4).
TABLE 2. ASCP TRAINING/GUIDANCE ON COVID-19 ( $\mathrm{N}=\mathbf{2 5 5})$

\begin{tabular}{|l|c|}
\hline $\begin{array}{l}\text { Percentage of ASCPs reporting training or guidance } \\
\text { on specific topic }\end{array}$ & 98 \\
\hline $\begin{array}{l}\text { Preventive strategies (hand washing practices, social } \\
\text { distance, self-quarantine, etc.) }\end{array}$ & 94 \\
\hline General information about COVID-19 & 95 \\
\hline Correct use of PPE (masks, gloves, apron, etc.) & 94 \\
\hline Signs and symptoms of COVID-19 & 66 \\
\hline Contact tracing and community surveillance & 65 \\
\hline Home based care of COVID-19 cases & 69 \\
\hline Continuity of community-based services & \\
\hline
\end{tabular}

TABLE 3. ASCP COVID-19 ACTIVITIES ( $N=261)$

\begin{tabular}{|l|c|}
\hline $\begin{array}{l}\text { Percentage of ASCPs engaged in COVID-19 activity } \\
\text { prevention or treatment }\end{array}$ & 99 \\
\hline $\begin{array}{l}\text { Educating communities/households about how to } \\
\text { take care of someone with COVID-19 in the home }\end{array}$ & 95 \\
\hline Referring suspected COVID-19 cases for testing & 30 \\
\hline Reporting suspected or confirmed cases of COVID-19 & 25 \\
\hline $\begin{array}{l}\text { Doing contract tracing for those who may have } \\
\text { COVID-19 in the community you serve }\end{array}$ & 35 \\
\hline $\begin{array}{l}\text { Referring suspected COVID-19 cases for advanced } \\
\text { care at facilities }\end{array}$ & 25 \\
\hline
\end{tabular}

TABLE 4. ASCP CHALLENGES ( $N=261)$

\begin{tabular}{|l|c|}
\hline Percentage of ASCPs reporting challenge & $\%$ \\
\hline $\begin{array}{l}\text { Cannot travel because of social distancing } \\
\text { regulations }\end{array}$ & 68 \\
\hline Do not have adequate PPE to feel safe & 56 \\
\hline People fear ASCP might spread COVID-19 & 56 \\
\hline ASCP fears they may get COVID-19 & 45 \\
\hline Had shortage of contraceptives & 46 \\
\hline Had shortage of drugs & 57 \\
\hline Had shortage of other commodities & 54 \\
\hline
\end{tabular}

\section{FIGURE 3. PERCENTAGE OF ASCPS GIVING SPECIFIC ADVICE ON PREVENTION AND TREATMENT (N= 259)}

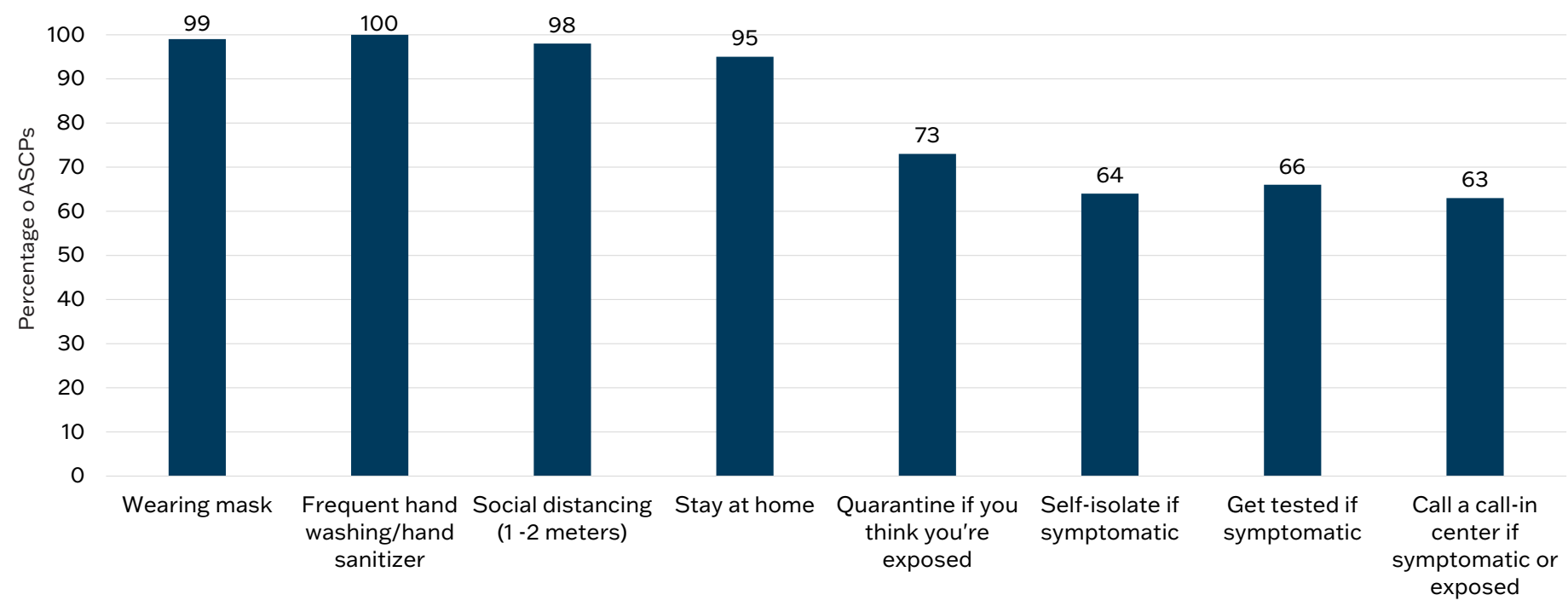


In addition to these challenges, $36 \%$ of ASCPs ( $n=94)$ reported experiencing "a little" or "a lot" of hostility or mistreatment by the community due to their work, such as having their messages ignored by clients or being refused entry into clients' homes. Twenty-six percent of ASCPs reported hostility or mistreatment by facility-based providers, (ignored referrals or being yelled at/spoken to rudely) (data not shown).

Although adequate PPE was cited as a challenge by the majority of ASCPs (Table 4), our data indicate that most were provided with PPE and other infection prevention supplies at some point in time (Table 5). How frequently and adequately these supplies are distributed warrants further exploration.

\section{CONCLUSION AND NEXT STEPS}

Our survey revealed that ASCPs are a critical source of education and care for their communities in Haiti during the pandemic. Already accustomed to providing care during emergencies such as natural disasters and disease outbreaks [2], ASCPs continue to demonstrate resilience throughout the COVID-19 pandemic.

In addition to carrying out their routine work, ASCPS provide a range of COVID-19 related education and services, including educating households on prevention and treatment, doing contract tracing in their communities, and referring clients to facilities for testing and advanced care. Our data reveal that ASCPs are receiving slightly less in-person supervision during the pandemic, however, levels of supportive supervision overall remain high.

ASCPs reported various challenges in their work such as inadequate provision of PPE and other supplies, some hostility and fear from communities, and their own fears of contracting and/or spreading COVID-19.

To improve ASCP knowledge, alleviate challenges, and provide greater support, we recommend policy and program stakeholders:

1. Ensure all ASCPs are given mandatory training on all aspects of COVID-19 education, treatment, and prevention, including concluding training on contract tracing, home-based care, and continuity of homebased services.

2. Provide ASCPs with regular and adequate PPE including masks, gloves, and hand sanitizer/soap to alleviate their own and the community's fears of contracting COVID-19.

3. Explore ASCPs' experiences of hostility at the community and provider levels further in future qualitative work.

4. Employ different channels of educating communities (ASCPs, media, virtual messaging) on misinformation and misconceptions around COVID-19.

\section{TABLE 5. PERCENTAGE OF ASCPS RECEIVING PPE} $(\mathrm{N}=261)$

\begin{tabular}{|l|c|}
\hline Percentage of ASCPs reporting receiving PPE & $\%$ \\
\hline Disposable masks & 80 \\
\hline Hand sanitizer & 98 \\
\hline Reusable masks & 99 \\
\hline Gloves & 99 \\
\hline Soap & 67 \\
\hline Cleaning/disinfecting supplies & 36 \\
\hline
\end{tabular}

\section{CONTACT}

$\begin{array}{ll}\text { Alain Casseus } & \text { Panmi Lasante, Haiti } \\ \text { acasseus@pih.org } & \text { Pop } \\ \text { Sarah Kennedy } & \text { Population Council, Washington, D.C. } \\ \text { skennedy@popcouncil.org }\end{array}$

\section{REFERENCES}

1. Agarwal S, Kirk K, Sripad P, Bellows B, Abuya T, CE Warren. (2019) Setting the global research agenda for community health systems: literature and consultative review. Hum Resour Health 17, 22. https:// doi.org/10.1186/s12960-019-0362-8

2. Sripad P, Casseus A, Kennedy S, Isaac B, Vissieres K, Warren CE, Ternier R. "Eternally restarting" or "a branch line of continuity"? Exploring consequences of external shocks on community health systems in Haiti. J Glob Health 2021;11:07004.

3. Ministry of Public Health and Population. https://mspp.gouv.ht/site/ downloads/16\%20nouvo\%20ka\%20COVID-19\%20ki\%20konfime\%20 nan $\% 20$ dat $\% 208 \% 20$ mas $\% 202021 \% 20$ an $\% 20$ nan $\% 20$ peyi $\% 20$ Dayiti.pdf

4. Frontline Health Project. 2020. Frontline Health: Harmonizing Metrics, Advancing Evidence, Accelerating Policy Project Overview Brief. Washington, D.C.: Population Council.

Suggested citation: Frontline Health Project. 2021. Exploring community health worker roles, supports, and experiences in the context of the COVID-19 pandemic in Haiti. Washington, D.C.: Population Council. 